THE THIRD HONORABLE MENTION ESBAT IN THE FOORTH DIMENSION COMPETITION.

BY "CBARLES HENRY 9MITH" (CARL A. RICHMOND, CHICAGO, ILL.) [It was one of the conditions of the Fourth Dimension Competition that the editor of the SCIENTIFIC AMRRICAN reserved the right to publish accordance with that condition, the essay which in the opnion of the judges, Profs. S. A. Mitchell and H. P. Manning, was deemed worthy of judges, Profs. . A. Mitchell and
third place in the honorable mention class is here printed.-E $\left.-E_{\text {D. }}\right]$

A colony of bees housed in a hive with glass walls so that their every movement can be observed affords a very instructive lesson in natural history. Such a glass hive may also serve as a helpful illustration in a consideration of the fourth dimension. Let us glass plates brought so close together that there is barely room for the bees to move about between them, and, for the purpose of our illustration, let us endow the bees with the intelligence of men. To these bees, so confined, forward and backward, right and left, would be familiar ideas and their world would be one of two dimensions only. Debarred from upward and downward movement by the closeness of the glass plates, the words "up" and "down" would be meaningless to them because there would be no experience upon which to base these ideas. Imperfect as is the illustration, it suggests the conception of a world of only two dimensions, length and breadth.

Plane geometry is a science which deals with such figures as triangles, squares, and circles. It is interesting to know that it originated in Egypt where it was developed to facilitate the measurement of land. This origin of the science gave rise to the name geometry, which means earth measurement. Long subsequent to the era of its Egyptian development the science was extended under the name of solid geometry to a study of such figures as spheres, cubes, and cones.

The bees in the glass hive could move around a square, could make triangles and circles, and to them plane geometry would be a practical science; but with their ignorance of an up-and-down direction, a cube or sphere would be inconceivable, and a third dimension would appear to them as absurd and unthinkable as a fourth dimension does to us. Suppose we lay two pencils on the table so as to cross one another at a right angle and then hold a third pencil so as to form right angles with the other two. While this is obviously a possible thing for us to do, it would be impossible for the bees with their ignorance of the dimension of height. They could, of course, have two slender pencils in their hive at a right angle to one another, but they could not have a third pencil at right angles to both of the first two. We may look upon the two pencils as representing the two dimensions of the world of the bees, and the three pencils as representing the three dimensions of our world. Suppose, further, that some one tells us to hold a fourth pencil at right angles with the other three. In our field of experience we can find no place for it, just as the bees could find no place in their field of experience for the third pencil. This fourth pencil represents the so-called fourth dimension. Although it is impossible for us to place it, the illustration of the relation of the bees to the third pencil or dimension teaches us that the limitations of experience ought not to be deemed conclusive as to how many dimensions space may have.

It is a matter of pure speculation as to whether there is such a thing as a fourth dimension, whether there are beings of intelligence to whom phenomena are manifested in the form of four dimensions. It is by no means the attitude of mathematicians to instantly recoil from the suggestion, but they are pleased to go ahead and study as accurately as possible under the necessary limitations what may be the propertie of a space of four dimensions, if there is any such thing. The fundamental guiding principle of their investigation is this: Whatever they find to be the relations of geometry of two dimensions to geometry of three dimensions, they assume that there are similar or analogous relations between geometry of three dimensions and geometry of four dimensions. As the circle is to the sphere, so is the sphere to some unknown body, which may have its existence in space of four dimensions. As the square is to the cube so is the cube to a figure in space of four dimension which we may call the "cuboid."

Of course the fourth dimension is intangible. Mathematicians do not ask us to imagine a fourth dimension, much less do they ask us to believe in it. It is not to be supposed that the most skilled student in this subject has a mental picture of four-dimensiona space. Nevertheless, the properties and relations of
figures existing in four-dimensional space may be investigated and stated.

Algebra is the science of numbers. It is a ver efficient aid in the study of geometry. Algebra deal largely with equations such as $x y=12$, which mean that $x$ and $y$ are two variable numbers that, multiplied together, give 12 , as for example, 3 and 4 or as the straight line and the circle may be represented by equations; in other words, the equations are condensed descriptions of the respective geometrical figures, somewhat as a score-card is a condensed de scription of a base-ball game. Mathematicians have learned that the properties of geometrical figures can be studied far more readily by means of their equations than by means of the figures themselves. mathematician who understands this mode of study can look at the equation of a curve and tell all sort of interesting and useful properties of it without ever seeing the curve itself-indeed, without even havin any mental picture of what the form of the curve may be.

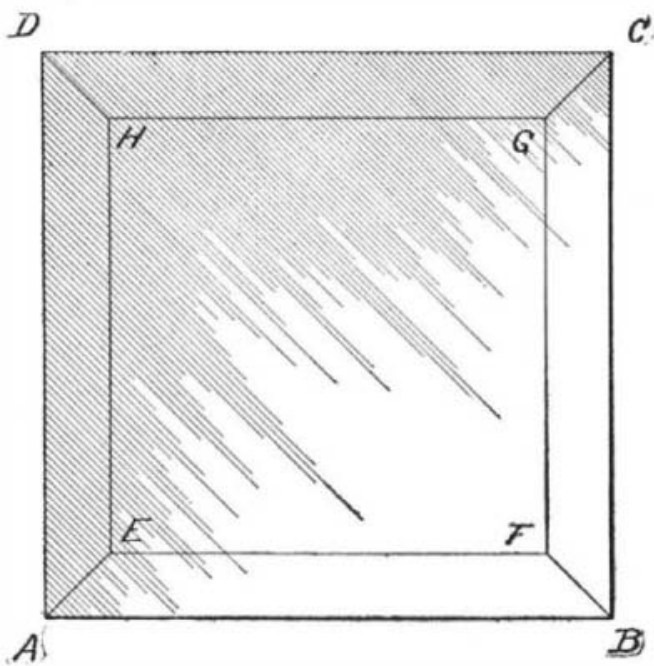

Top view of a glass cube as seen with one eye : a three-dimensional figure appearing in one plane.

Without going into detail, it may be stated that on equation with two variable numbers represents a plane figure, thus $x^{2}+y^{2}=15$ represents a circle. One equation with three variable numbers represents a figure in space, thus $x^{2}+y^{2}-z^{2}=0$ represents a cone. What does one equation with four variable numbers represent, say, for example, $x^{2}+y^{2}+z^{2}+$ $w^{2}=20$ ? By analogy, we should say a figure in space of four dimensions. Although we cannot imagine such a thing, we can pursue our analogies and study this unreal figure by means of its equation, and thus we can deduce many of its properties. The difference is simply this: whereas, when we study the equation of a cone, we can always turn to the real cone and interpret our results thereon, when we study an equation of a four-dimensional figure we have to be satisfied without such an interpretation. In other words, although our geometry halts with three dimensions our algebra marches on to any number of dimensions and is a stimulus to imagine a geometry of more than three dimensions.

We will now outline briefly a way in which algebra may help to give a person some faint notion of a figure having four dimensions. It is somewhat common to study a figure having three dimensions by means of equally spaced parallel sections thereof. For example, if the microscopist wants to study the shape and structure of a germ cell, he slices off exceedingly thin sections and arranges them in succession on a glass slide. Then by looking at these sections in succession he can form an idea of the solid structure of

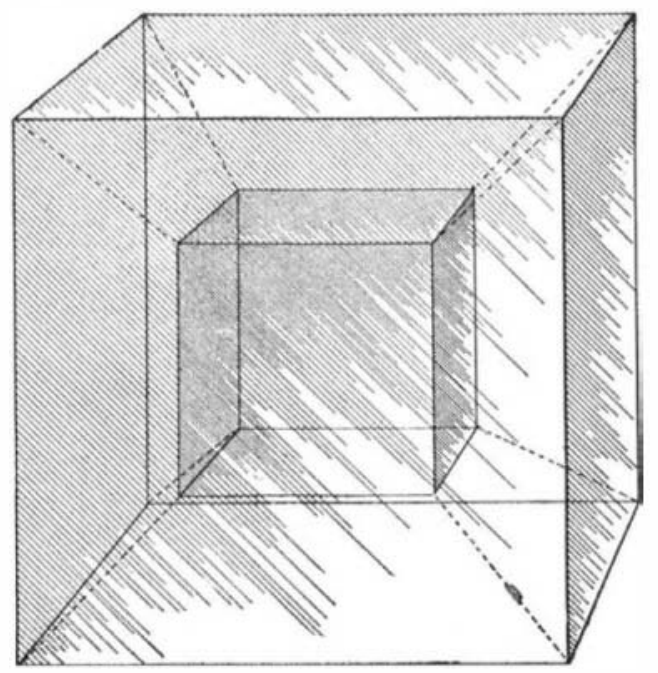

Analogous view of a "cuboid" of four dimension appearing as a figure of three dimensions.

the germ cell. Mathematicians have rules by which such sections of a solid figure may be constructed by means of equations. They start with an equation which represents a solid body, for example, $x^{2}+y^{2}+$ $z^{a}=9$ representing a sphere, and they perform certain operations by which they get a series of resulting equations that represent the successive sections of the solid body. It remains, then, merely to draw pictures of the sections from the data afforded by the result ing equations. By looking at all these pictures, a solid. In the case of a sphere the sections are circles of varying size. As we have already stated, an equation having four variable numbers, should by analogy represent a figure in space of four dimensions. Suppose we have such an equation, as $x^{2}+y^{2}+z^{2}+w^{2}$ $=20$. We can apply the same rules and perform the same operations to get sections of the figure represented by this equation. Curiously but consistently, these sections come out as solid figures. From the data afforded by the resulting equations, the mathematician can model these solid figures in clay and lay them in a row on the table before him. Just as the microscopist looks at the series of sections on his slide to get an idea of the solid structure of the germ cell, so the mathematician can look at the series of clay models before him and possibly feel that he has some idea of the nature of the four-dimensional figure represented by the equation with which he started.

Thus we see how the fourth dimension may be studied by means of the equations which algebra furnishes. There is another bolder way. We have seen that we can hold three pencils so that each one of them will make a right angle with each of the others. Instead of saying that it is absurd to suppose that a fourth pencil can be held in a position so as to form right angles with each of the first three pencils, let us assume that it can be done. Without any further assumptions a complete geometry of four dimensions can be built up by pure reasoning. Many of its conclusions are no more obvious to the senses than is the fundamental assumption with which it starts. Still that is the only assumption; all else may be deduced from that one assumption and from the principles of our well-known plane and solid geometry.

An illustration of a special method in the study of space of four dimensions may serve to show how mathematicians reason about such things without be ing able actually to imagine them. We proceed by ascertaining the relations between two dimensions and three dimensions, and then establishing these rela tions by analogy between three dimensions and four dimensions. Suppose we have a glass cube resting on the table before us and we close one eye and look straight down upon it with the open eye. Its appear ance will be as shown in the accompanying drawing. This drawing is really a plane figure, of two dimensions, and it might have been produced in the following manner; namely, by drawing one square inside of another and then drawing lines connecting the corresponding corners. All this could be done without any thought of three dimensions. The bees in the glass hive could draw such a figure as the one here on the paper before us. Nevertheless, on this figure many of the properties of the cube can be studied. By counting the four-sided figures $(A B C D, E F G H, A E F B$, $B F G C, C G H D, D H E A$ ), which we find to be six, we learn how many faces the cube has. By counting the corner points, which are eight, we learn how many corners the cube has. By counting the lines, which are twelve, we learn how many edges the cube has. Just as starting with the squares we are able to get a two dimensional figure, which, for the purposes of investigation, may be taken as representing the cube, may it not be possible that starting with cubes we can get a three-dimensional figure which shall represent the four-dimensional figure which we call the cuboid? Just as we drew a smaller square inside of a larger one, so we should think of a smaller cube inside of a larger cube, and just as we drew lines joining the corresponding corners in the case of the squares, so we should make planes joining corre sponding edges in the case of the cubes. The figure so formed is somewhat imperfectly pictured in the accompanying drawing, and for the sake of clearness, let us suppose we have such a solid glass figure before us. In the case of the squares, to find from them how many square faces the cube has, we counted the big outer square, the small inner square and the four surrounding figures and got six as the result. So in the case of the cubes, to find from them how many cube faces the cuboid has, we count the big outer cube, the small inner cube and the six surrounding solid bodies and thus get eight as the result; this indicates that the cuboid has eight cube faces. A further study of this representative figure discovers that the cuboid has 24 plane square faces, 32 edges and 16 corner points. This shows how we can get a representation of a fourdimensional body, and on this representation we can study its properties. There are many considerations which we have not space to present which confirm the accuracy of the deductions that have just been stated. What is the use of such generalities, abstractions and speculations? About the same as to know whethe the earth goes around the sun or the sun goes around the earth. Space is as properly an object of scientific study as are planets or geological strata. Moreover, the study of these fundamental things in geometry throws light on the nature of our own mental equipment. We learn better what is the nature of reasoning. processes and how knowledge is built up from simpler and more fundamental elements. Such speculations sometimes lead to very useful results.

If you hold 5 marbles in your hand and are told to 
take away 8 of them, this suggestion seems as unthinkable as the suggestion of a fourth dimension. subtracting 8 from 5 , instead of simply saying it impossible, then the foundation was laid for the enormously useful science of Algebra.

The assumption of a fourth dimension has not as yet led to any noteworthy useful results, but it is by no means impossible that the science of four-dimensional geometry may come to have useful applications. It has been suggested by Prof. Karl Pearson that an atom may be a plaee where ether is fiowing into our space from a space of four dimensions. It can be shown mathematically that this would explain many of the phenomena of matter. At the present stage, the suggestion is regarded, even by its author, as merely fanciful, though it is not as fanciful as the proposition of the German spiritualists who regard the fourth dimension as the abode of their disembodied spirits.

\section{SOME NEW WARSHIPS AND THEIR EQUIPMENT.} (Concluded from page 56.)

been entered upon seriously, and four battleships were laid down simultaneously in Baltic yards on June 16th. The "Sevastopol" and "Petropavlovsk" are building at the Baltic works and the "Poltava" and "Gangut" at the new Admiralty yard, the English firm of John Brown \& Co. being in charge of the work. On a displacement of 23,000 tons they will carry twelve 12-inch guns, arranged as shown, as well as sixteen 4.7's and four torpedo tubes. The speed will be 24 knots and the horse-power 42,000 , which is very high for battleships. Meanwhile four other battleships which were laid down in 1903-the "Imperator Pavel" and the "Andrei Pervozvanni" in the Baltic and the "Ioann Zlatoust" and "Evstafi" in the Black Sea-are still incomplete.

It is only four years since the first all-big-gun ship was laid down; but the following table will show how completely the idea has seized upon the naval powers. It shows the number of battleships of this type completed, under construction, or to be laid down this year:

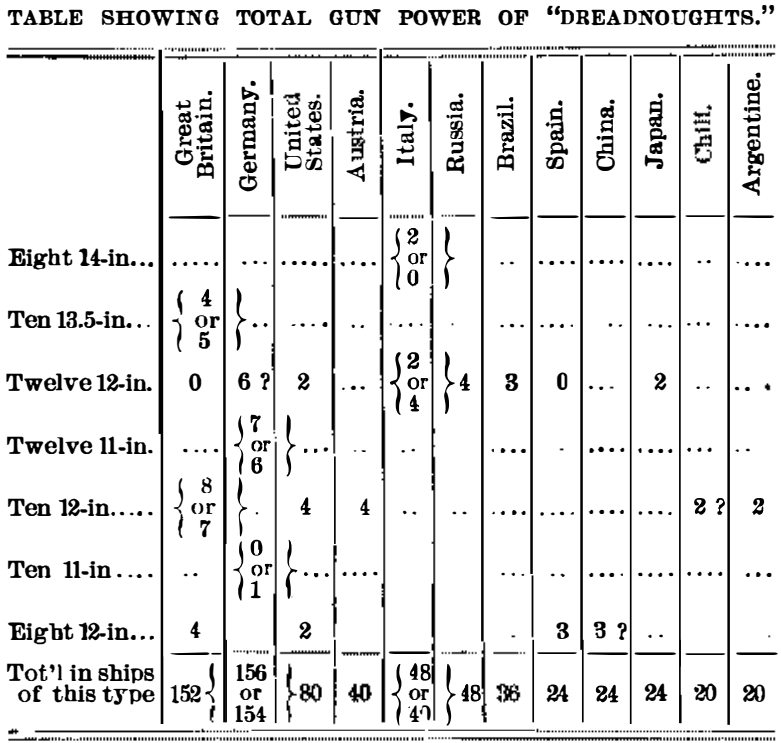

We also present a table which analyzes these vessels according to their main armament. It will be seen that, but for her four ships of this year's pro gramme, British designs would "put up a poor show."

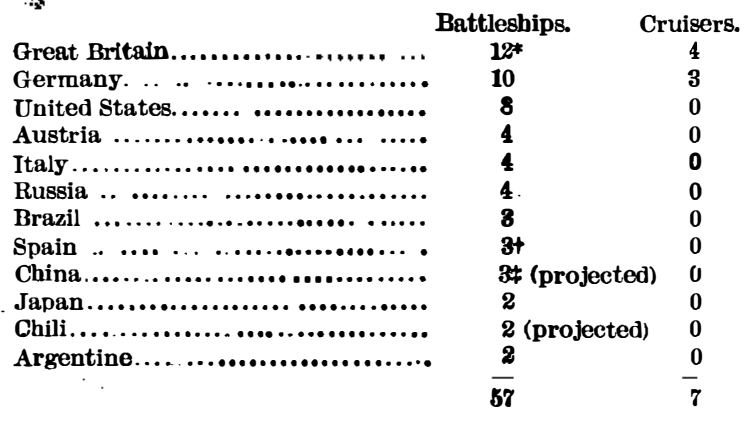

* Besides four " provisional" ships. + + Eight 12-inch. $\$ 15,000$ tons. Query "Dreadnought" type.

\section{OPENING OF THE DOWN-TOWN HODSON TONNELS.}

(Concluded from page 57.)

ng the eye, must afford a contrast generally garis and out of harmony with the otherwise excellent and subdued decoration.

This is doubtless a considerable source of income, difficult to forego in these commercial days; but considering the dignity and lack of ostentation with which the Hudson Companies have carried out both delicate negotiations and difficult engineering feats, considering also the immense profits likely to accrue from their undertakings, one might have hoped that they would omit this rather cheapening feature.

Stairways lead down from the concourse to the flve platforms below, at each of which in rotation, separ- ated by only $1 \frac{1}{2}$ minutes during "rush" hours, trains arrive by the southern and depart by the norther tube, there being no switching, and everything tending to the most rapid handling of traffic. Each train discharges its passengers upon the platform on one side of it and receives its new load from the platform at the other side, an arrangement which entirely separates incoming from outgoing passengers.

Again, below the rail level are extensive baggage and store rooms, and a subsidiary power station, making the Hudson Terminal Building a veritable city in itself, with clubs at the top, multitudinous business offices in between, a post office, telegraph office, and numerous shops below, and a railway station an power station in the basement, all inclosed within four walls.

\section{THE SCIENTIFIC WORK OF THE LATE PROF. SIMON \\ NEWCOMB.}

'Prof. Simon Newcomb died on July 11th in Washington at the age of 74 . His death has removed not only the most distinguished astronomer that America ever produced, but a man who is honored the world over for his monumental scientific achievements.

All Newcomb's work followed up with rare perseverance has constantly tended to this ideal end: First to arrive at a more exact knowledge of the magnitude serving as points of reference and then to establish the theory not only of all the planets but also of their satellites on a system of constants as precise as modern observations permit.

Shortly after he graduated from the Lawrence Scientific School at Cambridge, he began the first important problem with which his name is associated, namely, the motions and orbits of the asteroid which revolve about the sun between Mars and Jupiter. It was once thought that perhaps these numerous bodies might be fragments of a large planet whic had been shattered by explosion or collision. Were this true, the orbits would pass through the point at which the explosion occurred. As more and more asteroids were discovered, the coincidences of orbits became less marked. Still the theory was adhered to, because it was thought possible that the attraction of the larger planets might have caused perturbations. In order to decide for or against the theory, it wa necessary to discover general formulæ by which the positions of the orbits could be determined at any time in the past, so that it could be ascertained whether o not the orbits ever did pass through a common point of explosion, in which case it would be possible to give an approximate date for the catastrophe. As result of Newcomb's painstaking investigation, he concluded that the orbits had never passed through any point of common intersection. Later investigations based on Newcomb's work have shown that the hypothetical cataclysm never occurred, and that the asteroids probably always existed as minor planets. Th raper which Newcomb read on the subject at the Springfield meeting of the American Association fo the Advancement of Science in 1859 was the first that brought him into prominence-a young man of but twenty-four.

When Newcomb commenced his work at the Nava Observatory in 1861, the problems of the moon's mo tion had attracted astronomical attention. The most perfect lunar tables at the time were those of Hansen. Hansen had only a single assistant and could not, therefore, make the great number of observations required in the case of a body moving so rapidly as the moon. For a year or two Newcomb' observations showed that the moon seemed to be falling a little behind her predicted motion. This soon ceased, however, and she gradually forged ahead in a most remarkable way. In five or six years it wa apparent that this acceleration was becoming perma ent. Astronomers were puzzled to account for the phenomenon. For half a century the moon had apparently been running ahead and had then relaxed her speed so far as to fall behind again. Hansen had suggested that the planet Venus might be responsible for these inequalities. He showed that for 130 years the moon would thus be made to run ahead and for 130 years to fall behind. For 100 years the moon seemed to have followed Hansen's theory. Yet Newcomb found that the moon was deviating. To ascertain whether or not Hansen's tables represented the motion of the moon perfectly since 1750 , as astronomers supposed, Newcomb undertook an examination of the occultations of the moon with bright stars. It was not until the telescope had been introduced and used for finding the altitude of a heavenly body and not until the pendulum had been invented by Huyghens that the time of an occultation could be fixed with the required exactness-a task first systematically performed by French astronomers of the eighteenth century. Newcomb suspected that some accurate observations had been made before their time, which he might use in checking up Hansen's tables. He found that a few such observations had actually been made between 1660 and 1700 and discovered to his surprise that Hansen's tables were evidently much in error. But to de- termine the cause of the errors was impossible with out more observaticns. Newcomb planned a thorough search of the old records of Europe. On the occasion of the solar eclipse of 1870 , he was sent abroad to observe the phenomenon for the Naval Observatory. He seized the opportunity to go to Paris and consult the old records of the observatory there. After a search he found that the very observations he wanted had been made in great number by the Paris astronomers, both at the observatory and at other points in the city. Three or four years were spent in making calculations on the basis of these Parisian researches, when it was found that seventy-five years were added in a single step to the period during which the history of the moon's motions could be written. Before Newcomb's work this history was supposed to com mence with the observations of Bradley at Greenwich, about 1750. Now it was extended back to 1665 , and with a less degree of accuracy farther still. Hansen's tables were found to deviate from the truth in 1675 and subsequent years to a surprising extent. But the cause of the deviation is not entirely unfolded even

In 1877 Newcomb took charge of the Naval Almanac Office. He thoroughly reorganized the office and placed it upon a more scientific footing. He mapped out a programme of work which involved a discussion of all the observations of value on the positions of the sun, moon, and planets, and incidentally on the bright fixed stars, made at the leading observatories of the world since 1750 - a programme which involved a repetition, in the space of ten or fifteen years, of an important part of the world's work in astronomy for more than a century past. It was impossible to carry out this plan in all its completeness, so that Newcomb was obliged to confine himself to a correction of the reductions already made 'and published. For all that, the task was one which, in magnitude, probably exceeded any ever before attempted by any astronomer. The number of meridians observed on the sun, Mercury, Venus, and Mars alone numbered 62,030 . Still other branches of the Nautical Almanac Office work involved the computation of formula for the perturbation of the various pipnets by one another.

Important among the troublesome problems with which Newcomb had to deal while in charge of the Nautical Almanac was that of universal time. There was a day when every railroad had its own meridians by the time of which its trains were run, which had to be changed here and there in the case of the great trunk lines and which seldom agreed with the local time of a place. The passenger was constantly liable to miss a train, a connection, or an engagement by the doubt and confusion thus arising. All this was remedied in 1883 by the adoption of our present system of standard times of four different meridians, the introduction of which was one of the great reforms of our generation with which Newcomb's name is associated. When the change was made; Newcomb was in favor of using Washington time as a standard, in stead of Greenwich. But those who were pressing the measure thought it advisable to have a system for the whole world, and for this purpose the meridian of Greenwich was the natural one.

By 1894 Newcomb had succeeded in bringing so mueh of his work as pertained to the reduction of the observations and determination of the elements of the planets to a conclusion. So far as the general planets were concerned, it remained only to construct the necessary tables which, however, involved several years' work. Before Newcomb's time the confusion which pervaded the whole system of exact astronomy arising from the disclosures of the fundamental data employed by the astronomers of the various countries and various institutions in their work, was such that it was rather exceptional to base any astronomica result on entirely homogeneous and consistent data To remedy this state of things and to start the exact astronomy of the twentieth century on one basis for the whole world, was one of the plans which Newcomb had mapped out for himself when he took charge of the Nautical Almanac Office. Dr. N. W. Downing superintendent of the British Nautical Almanac, was animated by the same motive. He had especially in view the avoidance of duplicate work which arose from the same computations being made in different countries for the same result. The field of astron omy is so vast and the quantity of work required to be done so far beyond the power of any one nation that a combination to avoid all such waste was extremely desirable. When Newcomb published his preliminary results in 1895, Downing took the initiative in putting the idea into effect by proposing an international conference of the directors of the four leading ephemerides to agree upon a uniform system of data for all computations pertaining to the fixed stars This conference was held in Paris in May, 1896.

In 1902, when the Carnegie Institution was organized, it made a grant to supply Newcomb with computing assistants and other facilities necessary for the completion of his study of the moon's motions. 